\title{
Thrombectomy for acute ischemic stroke patients with isolated distal internal carotid artery occlusion: a retrospective observational study
}

\author{
Jan W. Hoving ${ }^{1}$ (D) $\cdot$ Manon Kappelhof ${ }^{1,2}$ (D) Mark Schembri $^{1}$ (D) $\cdot$ Bart J. Emmer $^{1}$ (D) Olvert A. Berkhemer $^{1}$ (D) \\ Adrien E. D. Groot ${ }^{3}$ (D) - Diederik W. J. Dippel ${ }^{4}$ - Wim H. van Zwam ${ }^{5}$ (1) - Jonathan M. Coutinho ${ }^{3}$ (D) \\ Henk A. Marquering ${ }^{1,2}$ (D) Charles B. L. M. Majoie ${ }^{1}$ (D) $\cdot$ René van den Berg ${ }^{1}$ (D) $\cdot$ for the MR CLEAN Registry Investigators
}

Received: 15 May 2020 / Accepted: 6 September 2020 / Published online: 7 October 2020

(C) The Author(s) 2020

\begin{abstract}
Purpose Acute stroke patients presenting with a distal internal carotid artery occlusion and patent carotid terminus, allowing for collateral flow via the circle of Willis, may have a more favorable natural history. Therefore, benefit of endovascular treatment (EVT) is less evident. We performed an exploratory analysis of EVT results compared to conservative treatment in patients with 'carotid-I' occlusions. Methods We report on EVT-treated and non-EVT-treated patients with carotid-I occlusions from the MR CLEAN Registry, MR CLEAN trial, and our comprehensive stroke center. CT-angiography was reviewed on primary collateral patency and choroid plexus enhancement. Perfusion deficits were assessed on CT-perfusion (CTP). Clot migration was assessed by comparing clot location on baseline CTA to its location on periprocedural digital subtraction angiography. Outcomes included 90-day functional independence (mRS 0-2), successful reperfusion and mortality.

Results We included 51 patients. Forty-one patients received EVT, ten patients did not. Intravenous thrombolysis was administered in $32(78 \%)$ EVT-treated patients and $6(60 \%)$ non-EVT-treated patients. CTP, available for 17 patients, showed hypoperfusion on cerebral blood flow maps in $13(76 \%)$ patients. Successful reperfusion after EVT occurred in $23(56 \%)$, and clot migration in 8 patients (20\%). Functional independence was achieved in 54\% (21/39) of EVT-treated and in 10\% (1/10) of non-EVT-treated patients. Mortality was 26\% (10/39) and 30\% (3/10), respectively. Anterior choroidal artery patency and choroid plexus enhancement were positively associated with functional independence.

Conclusion In our population, data suggest improved outcomes after EVT in carotid-I occlusion patients and provide no arguments to withhold EVT in these patients.
\end{abstract}

Keywords Stroke $\cdot$ Artery $\cdot$ Thrombectomy $\cdot$ CT angiography

JWH and MK contributed equally to this work.

Electronic supplementary material The online version of this article (https://doi.org/10.1007/s00234-020-02550-5) contains supplementary material, which is available to authorized users.

René van den Berg

r.vdberg@amsterdamumc.nl

1 Department of Radiology and Nuclear Medicine, Amsterdam UMC, University of Amsterdam, Amsterdam, The Netherlands

2 Department of Biomedical Engineering and Physics, Amsterdam UMC, University of Amsterdam, Amsterdam, The Netherlands

3 Department of Neurology, Amsterdam UMC, University of Amsterdam, Amsterdam, The Netherlands

4 Department of Neurology, Erasmus MC, Rotterdam, The Netherlands

5 Department of Radiology and Nuclear Medicine, Maastricht UMC, Maastricht, The Netherlands

\section{Introduction}

Multiple clinical trials have proven the benefit of endovascular treatment (EVT) in patients with acute ischemic stroke caused by proximal occlusions of the anterior circulation, up to as much as $24 \mathrm{~h}$ after stroke onset [1-4]. For certain patients, however, the benefit of EVT remains unclear. Acute occlusion of the distal intracranial internal carotid artery (ICA) with an open ICA-terminus allows for substantial collateral flow to the middle cerebral artery (MCA) via the circle of Willis, mostly through the anterior communicating artery (ACOM). This occlusion pattern was previously described as "carotid-I occlusion" [5]. Due to the primary collateral flow, the natural history of these occlusions might be more favorable and the benefits of EVT may therefore be limited. 
Several arguments can be made to either treat symptomatic patients with carotid-I occlusions with EVT or refrain from intervention and treat with intravenous thrombolysis (IVT) only, if eligible. Collateral flow in symptomatic patients with carotid-I occlusions is apparently not adequate with a risk for the development of watershed infarcts. In addition, proximal occlusion of the anterior choroidal artery branching off at the level of the distal ICA may cause internal capsule infarction, leading to worse outcome [6, 7]. Therefore, revascularization by IVT or EVT might be beneficial. However, early revascularization carries the risk of fragmentation or dislodgment of the clot into downstream territories leading to a more difficult disposition to reopen the territory involved [8]. Finally, symptoms may be caused by lacunar infarcts or distal occlusions not visible on CT-angiography (CTA), rather than the carotidI occlusion itself. These considerations could be arguments against EVT.

As of yet, little data is available on treatment results in patients with carotid-I occlusions as they form a very small proportion of patients in stroke publications. Only $13 \%$ of all patients with carotid occlusions had the "carotid-I" configuration in the MERCI and Multi-MERCI trials [5]. Although patients with a causative occlusion of the ICA or M1 segment should receive EVT according to the current AHA/ASA Guidelines, [9] this recommendation is based on data of seven large EVT trials, where the carotid-I occlusion type was either not studied separately from other distal ICA-occlusions [10-12] or underrepresented [13]. It is very unlikely that the carotid-I occlusion pattern was prevalent enough to be adequately represented in the treatment effect estimated in these trials, leaving the optimal treatment approach for carotid-I occlusions unclear. Therefore, we aimed to perform an exploratory comparison of EVT versus conservative treatment in patients with carotid-I occlusions.

\section{Methods}

\section{Patient inclusion}

This study compares individual patient data from patients with a carotid-I occlusion who were treated with EVT, to carotid-I occlusion patients not treated with EVT. EVT-treated cases were included from the MR CLEAN Registry between March 2014 and November 2017, and from the MR CLEAN trial intervention arm between December 2010 and March 2014 [10]. Non-EVT-treated cases were included from the MR CLEAN trial control arm and from a consecutive cohort of carotid-I occlusion patients admitted to our center between 2012 and April 2018. All patients were treated with IVT if they were eligible [9].

The MR CLEAN Registry is an observational, prospective registry of all patients undergoing EVT for acute ischemic stroke in the Netherlands [14]. From the total population, we included patients with an anterior circulation occlusion, aged 18 years or older, who were treated in a MR CLEAN trial center within $6.5 \mathrm{~h}$ of symptom onset. We included cases with an occlusion of the distal intracranial ICA, without additional intracranial occlusions on CTA. In addition, patients were excluded if image quality was too poor for adequate assessment.

The MR CLEAN trial was a randomized clinical trial comparing usual care plus EVT to usual care alone [9]. Included patients were 18 years or older, had an acute ischemic stroke caused by a proximal occlusion in an anterior circulation artery, and presented within $6 \mathrm{~h}$ of symptom onset.

For the current study, we included patients with an intracranial carotid-I occlusion without additional intracranial occlusions on CTA. Patients with isolated extracranial carotid occlusions were not included.

The carotid-I occlusion patients from our local cohort were not treated with EVT and not included in the MR CLEAN trial control arm. EVT was withheld in these cases at the discretion of the interventionist: the risk of clot migration towards patent downstream territories was judged too large, or the potential benefit gained with EVT too small.

\section{Image analysis}

All imaging was assessed by an independent core laboratory of (neuro)radiologists [10]. The current study used core lab data on early ischemic changes (Alberta Stroke Program Early CT Score; ASPECTS) on non-contrast CT (NCCT), CTA occlusion location (including possible intracranial occlusions distal to the carotid-I occlusion) and collateral score, reperfusion after EVT as assessed on digital subtraction angiography (DSA) images, and presence of symptomatic intracranial hemorrhage on follow-up NCCT.

For patients included in the current study, additional imaging assessments were performed by one experienced interventional neuroradiologist, who was blinded to all clinical information. Baseline NCCT and CTA images, as well as DSA images, were used to confirm presence of an intracranial carotid-I occlusion. We defined presence of a carotid-I occlusion as presence of contrast in the A1, carotid terminus, and M1 segments, with evidence of an intracranial thrombus in the distal ICA, from NCCT hyperdense artery sign, and/or CTA contrast cut-off, supported by DSA runs acquired before the first thrombectomy attempt.

Baseline CTA images were evaluated for patency of specific vessel segments relevant to the primary collateral circulation: the supra- and infraclinoid ICA, posterior cerebral artery (PCA) segment 1, ACOM, and left and right ACA segment 1 , posterior communicating artery $(\mathrm{PCOM})$, anterior choroidal artery (AChA), and ophthalmic artery. Absence of plexus enhancement of the choroid plexus in the temporal horn was assessed as a possible indirect sign for AChA 
occlusion. In addition, DSA images were compared with baseline CTA images to check for clot migration to distal territory. Furthermore, hypoperfusion, as measured by the cerebral blood flow (CBF) and cerebral blood volume (CBV), was assessed on baseline $\mathrm{CT}$ perfusion (CTP) for cases where CTP images were acquired.

\section{Outcome measures}

Our primary outcome was 90-day functional independence (modified Rankin Scale score [mRS] 0-2). Secondary outcomes were ordinal 90-day $\mathrm{mRS}$, mortality, successful reperfusion after EVT (extended thrombolysis in cerebral infarction [eTICI] score 2B-3), clot migration during EVT, delta-NIHSS (baseline-24 h NIHSS), and symptomatic intracranial hemorrhage ( $\mathrm{sICH}$ ), defined as a $\geq 4$-point increase on the NIHSS and intracranial hemorrhage on follow-up NCCT.

\section{Statistical analysis}

Because of low patient numbers, we performed descriptive, exploratory analyses only-no regression analyses or statistical testing could reliably be performed. Baseline, imaging, and outcome characteristics were compared between carotidI occlusion cases treated with EVT and cases treated conservatively. In addition, we compared EVT-treated carotid-I occlusion cases with the overall MR CLEAN Registry population. Continuous variables were summarized as medians with interquartile ranges (IQR); categorical variables were noted as counts and percentages with $95 \%$ confidence intervals. All analyses were performed using R version 3.5.2 (R Foundation for Statistical Computing, Vienna, Austria).

\section{Results}

A total of 51 patients met the inclusion criteria for this study: 41 underwent EVT (40/3352 [1\%] of the MR CLEAN Registry patients; $1 / 500$ [0.2\%] of the MR CLEAN trial patients), ten did not (4 MR CLEAN trial patients, 6 local cohort) (Online Resource 1). Baseline patient characteristics compared with the overall Registry cohort are detailed in Table 1. Most patients were male $(37 / 51 ; 73 \%)$. IVT was administered in 38 of $51(75 \%)$ included patients. Four patients $(8 \%)$ were treated with supportive care only. Patients did not receive IVT either due to presentation outside of the 4.5-h time window (5/13 patients [38\%]) or due to contraindications like recent surgery $(1 / 13,8 \%)$ for oral anticoagulation use $(7 / 13,54 \%)$. Baseline characteristics within each group divided by IVT-treatment are shown in Online Resource 2.

\section{Clinical outcomes}

Table 2 shows clinical outcomes for EVT- versus nonEVT-treated patients. In our total population, data on 90day functional outcomes were available for 49/51 (96\%) patients. Twenty-two (43\%) patients achieved functional independence compared with $38 \%$ (1200/3180) of patients in the overall MR CLEAN Registry cohort (Table 1). Overall, improved functional outcomes were observed in the EVT-treated group (Fig. 1). Functional independence after EVT was achieved in 14/23 (61\%) of cases with successful reperfusion versus $7 / 18(38 \%)$ of cases with unsuccessful reperfusion. In comparison, functional independence was achieved in 186/632 (29\%) of Registry patients with carotid-T/L occlusions. Non-EVT-treated patients achieved functional independence in 1/10 (10\%) of cases. Details on median delta-NIHSS, mortality at 90 days, and sICH are displayed in Table 2.

\section{Imaging findings}

A detailed overview of all imaging variables, subcategorized for EVT- versus non-EVT-treated patients, is shown in Table 2. In our total population, initial (pretreatment)noncontrast CT scan showed hypodensity in the ipsilateral hemisphere in 15/51 (29\%) patients. Enhancement of the choroid plexus was found in 40/51 (78\%) patients. Higher rates of functional independence were seen in EVT-treated patients with patency of the anterior choroidal artery (63 vs. 50\%), patency of the ophthalmic artery (67 vs. 50\%), a complete circle of Willis ( 50 vs. $42 \%$ ), and choroid plexus enhancement (56 vs. $50 \%)$.

CTP was available in 17/51 patients (33\%). Hypoperfusion, as measured with $\mathrm{CBF}$, was seen in 13 patients (Table 2). A core infarct, as measured with $\mathrm{CBV}$, was visible in 10 patients. In all cases, perfusion deficit on CTP involved the entire hemisphere or multiple flow areas. Of the 10 patients with a core infarct visible on $\mathrm{CTP}$, five patients showed $\mathrm{CBF} / \mathrm{CBV}$ mismatch indicating presence of a penumbra.

Procedural details on EVT treated patients are given in Online Resource 3 in eight (20\%) EVT-treated patients, clot migration to the proximal MCA, ACA, or PCA branches had occurred during the procedure, with failure to remove the dislodged clot. In five of these patients, the distal embolus was located in the MCA territory-none of these patients were functionally independent at 3 months post-stroke. In the other three cases, clot fragmentation and migration occurred into the ACA and/or PCA territory. Three-month outcome was mRS 1 for one of these patients and mRS 4 in the other two.

Occlusion location on the first run of DSA differed from the CTA occlusion location for two cases in our study: both clots had migrated from the carotid top to the proximal M1 segment and were successfully removed during EVT. 
Table 1 Patient baseline characteristics

\begin{tabular}{|c|c|c|c|}
\hline & $\operatorname{EVT}[N=41]$ & $\begin{array}{l}\text { Non-EVT } \\
{[N=10]}\end{array}$ & $\begin{array}{l}\text { Registry overall } \\
{[N=3180]}\end{array}$ \\
\hline Age (year), median (IQR) & $62(55-76)$ & $83(76-85)$ & $72(61-81)$ \\
\hline Male, $n(\% ; 95 \% \mathrm{CI})$ & $30(73 ; 58-84)$ & $7(70 ; 40-89)$ & $1654(52 ; 50-54)$ \\
\hline Baseline NIHSS, median (IQR) [known in] & $\begin{array}{l}15(8-21) \\
\quad[N=40]\end{array}$ & $17(14-21)$ & $\begin{array}{l}16(11-19) \\
\quad[N=3128]\end{array}$ \\
\hline Left hemisphere, $n(\% ; 95 \% \mathrm{CI})$ & $30(73 ; 58-84)$ & $5(50 ; 24-76)$ & $1686(53 ; 51-55)$ \\
\hline Hypertension, $n(\% ; 95 \% \mathrm{CI})[$ known in] & $\begin{array}{l}12(30 ; 18-45) \\
\quad[N=40]\end{array}$ & $4(40 ; 17-69)$ & $\begin{array}{c}1633(52 ; 51-54) \\
\quad[N=3118]\end{array}$ \\
\hline Atrial fibrillation, $n(\% ; 95 \% \mathrm{CI})[$ known in] & $6(14 ; 7-28)$ & $4(40 ; 17-69)$ & $\begin{array}{l}756(24 ; 23-26) \\
\quad[N=3138]\end{array}$ \\
\hline Myocardial infarction, $n(\% ; 95 \% \mathrm{CI})[$ known in $]$ & $8(20 ; 10-34)$ & $2(20 ; 6-0.51)$ & $\begin{array}{l}441(14 ; 13-15) \\
\quad[N=3116]\end{array}$ \\
\hline Diabetes mellitus, $n(\% ; 95 \% \mathrm{CI})$ [known in] & $5(12 ; 5-26)$ & $3(30 ; 11-60)$ & $\begin{array}{c}510(16 ; 15-17) \\
\quad[N=3156]\end{array}$ \\
\hline Pre-stroke mRS, median (IQR) & $0(0-0)$ & $1(0-3)$ & $0(0-1)$ \\
\hline $\begin{array}{l}\text { Blood glucose level (mmol/l), median (IQR) } \\
\text { [known in] }\end{array}$ & $\begin{array}{c}6.4(5.8-7.4) \\
{[N=40]}\end{array}$ & $6.9(5.9-9.2)$ & $\begin{array}{l}6.8(5.9-8.1) \\
\quad[N=2813]\end{array}$ \\
\hline Smoking history, $n(\% ; 95 \% \mathrm{CI})[$ known in] & $\begin{array}{l}12(29 ; 20-50) \\
{[N=36]}\end{array}$ & $1(10 ; 2-40)$ & $\begin{array}{l}677(28 ; 26-30) \\
\quad[N=2440]\end{array}$ \\
\hline $\begin{array}{l}\text { Systolic blood pressure at baseline }(\mathrm{mmHg}), \\
\text { median (IQR) [known in] }\end{array}$ & $\begin{array}{l}151(126-170) \\
\quad[N=40]\end{array}$ & 132(87-154) & $\begin{array}{c}150(132-165) \\
{[N=3092]}\end{array}$ \\
\hline $\begin{array}{l}\text { Diastolic blood pressure at baseline }(\mathrm{mmHg}), \\
\text { median (IQR) [known in] }\end{array}$ & $\begin{array}{r}87(73-94) \\
{[N=40]}\end{array}$ & $80(65-90)$ & $\begin{array}{l}80(71-91) \\
\quad[N=3084]\end{array}$ \\
\hline IVT administered, $n(\% ; 95 \% \mathrm{CI})[$ known in] & $32(78 ; 63-88)$ & $6(60 ; 31-83)$ & $\begin{array}{l}2427(77 ; 75-78) \\
\quad[N=3169]\end{array}$ \\
\hline $\begin{array}{l}\text { Onset-to-presentation time (min), median (IQR) } \\
{[\text { known in }]}\end{array}$ & $\begin{array}{c}67(47-165) \\
{[N=33]}\end{array}$ & $\begin{array}{l}70(58-101) \\
\quad[N=9]\end{array}$ & $\begin{array}{l}55(38-96) \\
\quad[N=2572]\end{array}$ \\
\hline Door-to-needle time for IVT (min), median (IQR) & $\begin{array}{r}25(20-36) \\
{[N=31]}\end{array}$ & $\begin{array}{c}34(24-56) \\
{[N=6]}\end{array}$ & $\begin{array}{l}24(18-33) \\
\quad[N=1919]\end{array}$ \\
\hline $\begin{array}{l}\text { Onset-to-groin puncture time for EVT (min), } \\
\text { median (IQR) [known in] }\end{array}$ & $225(172-306)$ & NA & $\begin{array}{c}195(150-260) \\
{[N=3264]}\end{array}$ \\
\hline
\end{tabular}

If the [known in] number is not shown, the variable was known in all patients. $95 \% \mathrm{CI}$ in italics

$E V T$ endovascular treatment, $I V T$ intravenous thrombolysis, $I Q R$ interquartile range, $m R S$ modified Rankin Scale, $N$ number of patients, NIHSS National Institute of Health Stroke Scale, SD standard deviation

\section{Illustrative case}

A 63-year-old patient was admitted $3 \mathrm{~h}$ after last seen well with right-sided paralysis and speech difficulties. Medical history was unremarkable for cardiovascular events and risk factors. Initial neurological examination showed an NIHSS of 20. A gaze paresis with horizontal eye deviation towards the left side was present together with a right-sided facial palsy without upper face involvement, a complete paralysis of the right arm and paresis of the right leg, and a right-sided hemianopia. NCCT showed a subtle area of hypo-attenuation in the left medial temporal lobe and posterior limb of the internal capsule (Fig. 2a). Baseline ASPECTS was 7. CTA at presentation showed a distal ICA occlusion but normal patency of the MCA, ACA, and PCA (Fig. 2b). Moreover, CTA showed only faint enhancement of the left choroid plexus and patent left PCOM and PCA (Fig. 2c). CTP data were post-processed using Philips Extended Brilliance Workspace v3.5 (Philips Healthcare, Best, Netherlands). CBF and CBV maps showed impaired perfusion on CTP in the left genu/posterior limb of the internal capsule and lentiform nucleus. (Fig. 2d, e). The patient received IVT as per protocol but lacked clinical improvement. No EVT was performed as the patient was allocated to the control arm of a randomized trial. The patient had no adverse events during admission and showed mild clinical improvement (NIHSS at discharge 17). Follow-up CTA showed no recanalization of the primary occlusion. Followup NCCT showed a large infarct of the medial part of the temporal lobe and posterior limb of the internal capsule (Fig. 2f). The extent of the infarct can be attributed to the occlusion of the anterior choroidal artery, which also supplies a large cortical territory. At 3 months follow-up, the patient was unable to walk unassisted, required help with daily activities, and was unable to live independently, corresponding to mRS 3 . 
Table 2 Outcome data and imaging variables

\begin{tabular}{|c|c|c|c|}
\hline & $\operatorname{EVT}[N=41]$ & $\begin{array}{l}\text { Non-EVT } \\
{[N=10]}\end{array}$ & $\begin{array}{l}\text { Registry overall } \\
{[N=3180]}\end{array}$ \\
\hline $\begin{array}{l}\text { Functional independence (mRS } 0-2) \text { at } 90 \text { days, } \\
n(\% ; 95 \% \mathrm{CI})[\text { known in] }\end{array}$ & $\begin{array}{l}21(54 ; 39-68) \\
\quad[N=39]\end{array}$ & $1(10 ; 2-40)$ & $\begin{array}{c}1200(40 ; 39-42) \\
{[N=2968]}\end{array}$ \\
\hline Ordinal mRS at 90 days, median (IQR) [known in] & $2(1-6)[N=39]$ & $5(4-6)$ & $3(2-6)[N=2968]$ \\
\hline $\begin{array}{l}\text { Successful reperfusion after EVT, } n(\% ; 95 \% \mathrm{CI}) \\
\text { [known in] }\end{array}$ & $23(56 ; 41-70)$ & NA & $\begin{array}{l}1913(62 ; 60-63) \\
\quad[N=3096]\end{array}$ \\
\hline Mortality at 90 days, $n(\% ; 95 \% \mathrm{CI})[\mathrm{known}$ in] & $\begin{array}{l}10(26 ; 15-41) \\
\quad[N=39]\end{array}$ & $3(30 ; 11-60)$ & $\begin{array}{l}863(29 ; 27-31) \\
\quad[N=2968]\end{array}$ \\
\hline Delta-NIHSS at $24 \mathrm{~h}$, median (IQR) [known in] & $\begin{array}{l}6(0-11) \\
\quad[N=38]\end{array}$ & $4(3-9)[N=8]$ & $4(0-9)[N=2838]$ \\
\hline $\mathrm{sICH}, n(\% ; 95 \% \mathrm{CI})$ & $2(5 ; 1-16)$ & $1(10 ; 2-40)$ & $188(6 ; 5-7)$ \\
\hline Patency of the infraclinoidal ICA, $n(\% ; 95 \% \mathrm{CI})$ & $5(12 ; 5-26)$ & $8(80 ; 49-94)$ & NA \\
\hline Patency of the supraclinoidal ICA, $n(\% ; 95 \% \mathrm{CI})$ & $13(32 ; 20-47)$ & $7(70 ; 40-89)$ & NA \\
\hline Patency of the PCOM, $n(\% ; 95 \% \mathrm{CI})$ & $14(34 ; 22-49)$ & $6(60 ; 31-83)$ & NA \\
\hline Patency of the ACOM, $n(\% ; 95 \% \mathrm{CI})$ & $38(93 ; 81.97)$ & $\begin{array}{l}10(100 \\
\quad 72-100)\end{array}$ & NA \\
\hline $\begin{array}{l}\text { Patency of the ACOM and PCOM (complete circle } \\
\text { of Willis), } n(\% ; 95 \% \mathrm{CI})\end{array}$ & $26(63 ; 48-76)$ & $4(40 ; 17-69)$ & NA \\
\hline Patency of the AChA, $n(\% ; 95 \% \mathrm{CI})$ & $18(44 ; 30-59)$ & $3(30 ; 11-60)$ & NA \\
\hline Patency of the ophthalmic artery, $n(\% ; 95 \% \mathrm{CI})$ & $14(34 ; 22-49)$ & $3(30 ; 11-60)$ & NA \\
\hline Plexus enhancement, $n(\% ; 95 \% \mathrm{CI})$ & $35(85 ; 72-93)$ & $5(50 ; 24-76)$ & NA \\
\hline Hypodensity on $\mathrm{NCCT}^{*}, n(\% ; 95 \% \mathrm{CI})$ & $10(24 ; 14-39)$ & $5(50 ; 24-76)$ & NA \\
\hline Hypodensity in internal capsule, $n(\% ; 95 \% \mathrm{CI})$ & $3(7 ; 3-19)$ & $4(40 ; 17-69)$ & NA \\
\hline ASPECTS at baseline, median (IQR) [known in] & $\begin{array}{l}10(9-10) \\
\quad[N=39]\end{array}$ & $9(8-10)[N=9]$ & NA \\
\hline Collateral score, median (IQR) [known in] & $3(2-3)[N=37]$ & $\begin{array}{l}3(2.5-3) \\
\quad[N=3]\end{array}$ & NA \\
\hline CBV reduction on CTP, $n(\% ; 95 \% \mathrm{CI})[$ known in] & $\begin{array}{l}5(50 ; 24-76) \\
\quad[N=10]\end{array}$ & $\begin{array}{c}5(71 ; 36-92) \\
{[N=7]}\end{array}$ & NA \\
\hline $\mathrm{CBF}$ reduction on CTP, $n(\% ; 95 \% \mathrm{CI})[$ known in] & $\begin{array}{l}6(60 ; 31-83) \\
\quad[N=10]\end{array}$ & $\begin{array}{l}7(100 ; 65-100) \\
\quad[N=7]\end{array}$ & NA \\
\hline $\begin{array}{l}\mathrm{CBF} / \mathrm{CBV} \text { mismatch on } \mathrm{CTP}, n(\% ; 95 \% \mathrm{CI}) \\
{[\text { known in }]}\end{array}$ & $\begin{array}{l}5(50 ; 24-76) \\
\quad[N=10]\end{array}$ & $\begin{array}{l}3(43 ; 16-75) \\
\quad[N=7]\end{array}$ & NA \\
\hline
\end{tabular}

If the [known in] number is not shown, the variable was known in all patients. 95\% CI in italics

$A c h A$ anterior choroidal artery, $A C O M$ anterior communicating artery, $C B F$ cerebral blood flow, $C B V$ cerebral blood volume, CTP CT perfusion, Delta-NIHSS NIHSS at baseline minus NIHSS at $24 \mathrm{~h}$ after stroke, EVT endovascular treatment, $I C A$ internal carotid artery, IQR interquartile range, $I V T$ intravenous thrombolysis, $M I$ first segment of middle cerebral artery, min minutes, $m R S$ modified Rankin Scale score, $N$ number of patients, $N A$ not applicable/available, NIHSS National Institute of Health Stroke Scale, $s I C H$ symptomatic intracranial hemorrhage

$*$ Hypodensity on NCCT is defined as ASPECTS $\leq 9$

\section{Discussion}

This explorative study examining the results of EVT in patients with ischemic stroke due to isolated distal internal carotid artery occlusion ("carotid-I occlusion") suggests increased rates of functional independence and decreased mortality rates after EVT compared with conservative treatment, including IVT if patients are eligible.

Severe neurological deficits in cases of carotid-I occlusion with crossflow circulation through the circle of Willis and a patent ACA and MCA can be explained by hemodynamic dysfunction of the circle of Willis, leading to watershed infarcts, or by infarction of the anterior choroidal artery territory.
Alternatively, neurological deficit in carotid-I occlusion cases may be, at least partially, explained by small cortical thrombi in the distal vasculature. However, CTP in our patients showed perfusion deficits in the entire hemisphere or multiple flow territories, making the observed loss of function more likely attributable to a proximal occlusion. Moreover, rates of functional independence in patients without successful reperfusion were considerably lower than those in patients with successful reperfusion, indicating benefit of successful removal of carotid-I thrombi.

Although EVT is a well-proven indication for large vessel occlusions including distal ICA and MCA occlusions according to most recent guidelines [9], carotid-I occlusion should be considered as a different entity. The risk of treatment is much higher 


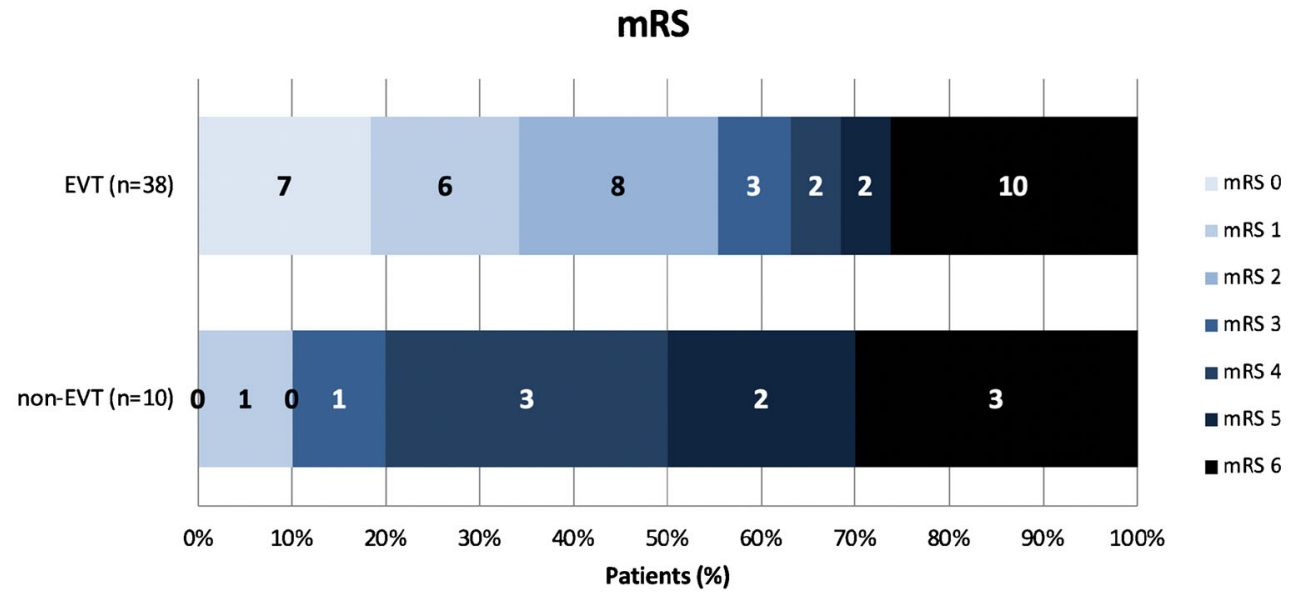

Fig. 1 Comparative plot of the modified Rankin Scale (mRS) showing clinical outcomes for EVT- and Non EVT groups. 90-day mRS data was available for 38 patients in the EVT-treated group EVT=endovascular treatment, $\mathrm{mRS}=$ modified Rankin Scale score. Numbers in bars represent number of patients with corresponding $\mathrm{mRS}$ score in patients with a patent intracranial circulation due to the risk of distal clot migration than in patients with a complete flow arrest. When clot migration occurred during the procedure, patients in our sample showed poor outcomes. Clot migration rates may decrease over time with evolving interventional techniques, potentially resulting in further improved outcomes after EVT in future patients with carotid-I occlusions. In addition, the exact stroke target can be either restoration of the diminished hemispheric perfusion or reopening of the occluded anterior choroidal territory, occlusion of which might lead to more definitive, irreversible neurological deficits.

Current AHA/ASA guidelines do recommend EVT for patients with intracranial ICA occlusions [9]. However, these recommendations are based on the large EVT trials. Of those, the MR CLEAN ( $n=500)$, ESCAPE $(n=316)$, and SWIFT PRIME $(n=196)$ trials only specified carotid-T, carotid-L/T, and carotid-T occlusions in their inclusion criteria, respectively, and did not describe carotid-I occlusion cases separately [10-12]. In the REVASCAT trial $(n=206)$, carotid-I occlusions were mentioned as a separate group, resulting in one single patient with this occlusion type included in the control group. Since the intracranial collateral circulation is sustained in carotid-I occlusions through the circle of Willis, a more favorable natural course and smaller EVT benefit may be expected. Hence, the treatment effect of EVT in carotid-I occlusions cannot be concluded from the large EVT trial results.

Previous studies on carotid-I occlusions report on a limited number of patients. First, Liebeskind et al. described nine carotid-I occlusion cases treated with the Merci Retrieval System [5]. They reported a lower rate of functional independence at 90 days of $38 \%$, possibly due to the use of an older generation thrombectomy device. Second, a recent study by Kim et al. assessed treatment results in a Korean population with ICA occlusion and patent collateral MCA flow, with or without additional intracranial occlusions [15]. They included eight patients with carotid-I occlusions treated with medical treatment only and 27 treated with EVT, but unfortunately, no outcome data on the carotid-I subgroup was presented. Third, a recent study in a Japanese population found poorer outcomes in carotid-I occlusion patients with clot migration before or during EVT, corresponding to our observations on clot migration [16].

Good collateral flow through the ACOM or PCOM can effectively sustain the viability of the brain parenchyma without causing any kind of neurological deficit in carotid-I occlusions, as is observed in balloon occlusion testing before permanent occlusion of the ICA to treat carotid aneurysms [17]. Without prior balloon occlusion testing, approximately $70 \%$ of patients will remain asymptomatic [17]. Hence, approximately $70 \%$ of the general population can be expected to not show any clinical symptoms in case of an acute distal carotid-I occlusion. If a patient presents with an acute neurological deficit and a carotid-I occlusion, this implies hypoperfusion. Hypoperfusion in this setting can be caused by failure of the collateral system, with or without concomitant cortical infarction due to distal thrombi. Patients with more severe strokes at baseline can hence be expected to have more circle of Willis anomalies, as was confirmed in this study's imaging readings. Even in situations where only minor deficits are present, prolonged hypoperfusion may finally lead to progressive neurological deficits if treatment is withheld [18-22]. Also, carotid-I occlusions secondary to atherosclerotic plaque may be more challenging technically and lead to less favorable outcome rates compared with carotid-I occlusions of embolic origin [23].

Theoretically, CTP imaging could depict the extent of the territory at risk, pointing to the necessity of urgent revascularization of the distal ICA, even if all intracranial arteries are patent on CTA. CTP could also show perfusion deficits in the internal capsule and other AChA-related territories. Unfortunately, CTP imaging was only available in one third of EVT-treated patients. Hypoperfusion on CTP, as measured by both CBF and CBV, could give support to start EVT, although the results in our patient sample should be 


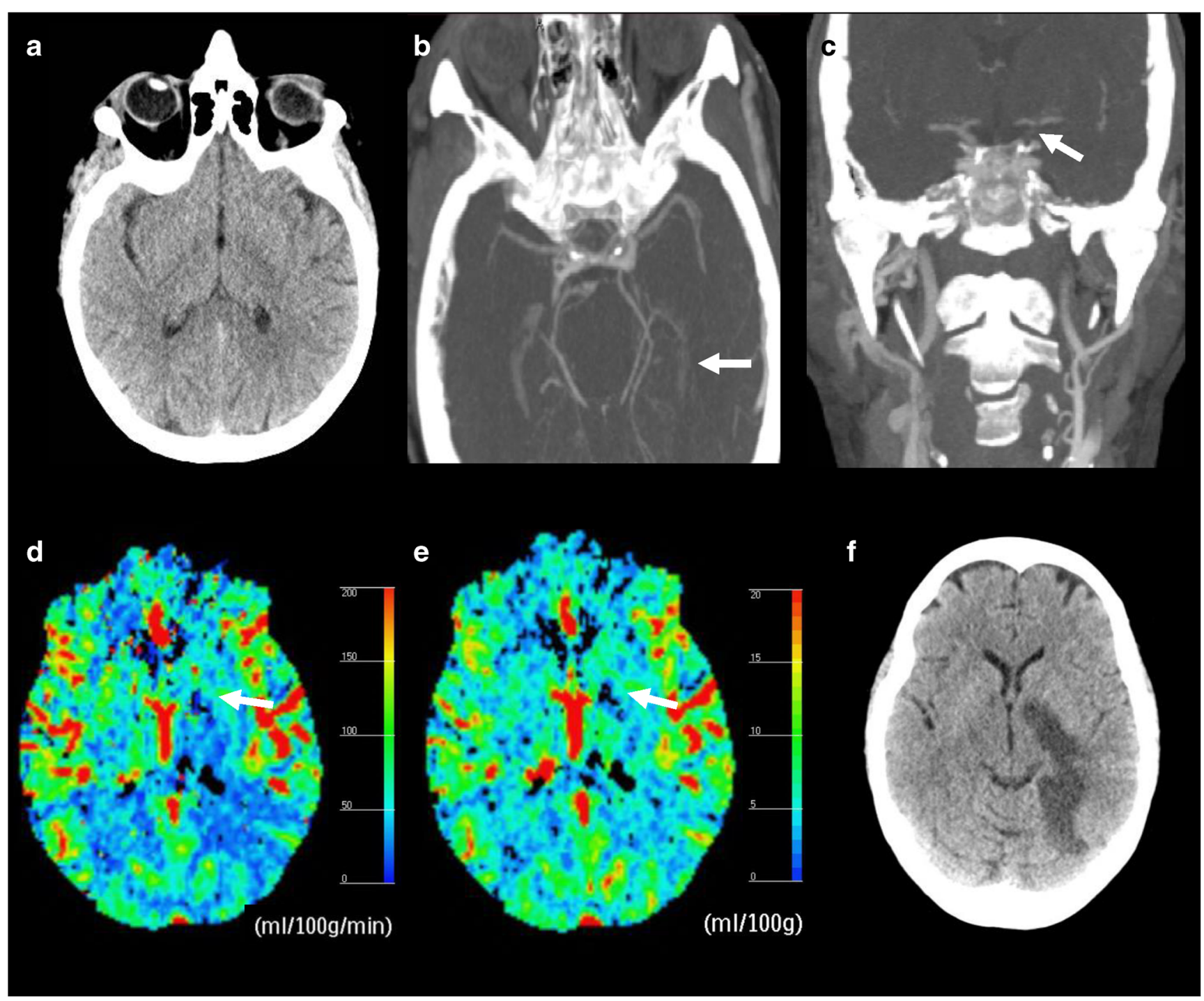

Fig. 2 Illustrative case a: Baseline non-contrast CT showing subtle region of hypo-attenuation in the left medial temporal lobe and posterior limb of the internal capsule. b: Near-absent enhancement of left choroid plexus (arrow) and patent PCOM and PCA. c: Coronal CT-angiography MIP shows distal left carotid-I occlusion (arrow) with patent middle and anterior cerebral arteries. d: Cerebral blood flow map of CT perfusion

interpreted cautiously given that in our population only 6/17EVTtreated patients showed hypoperfusion on CTP.

If no CTP imaging is available, CTA can show lack of enhancement of the choroid plexus, pointing to a perfusion problem in the AChA territory [22]. Presence of a clot at the distal ICA can occlude the origin of the AChA. Emboli or insufficient collateral supply can subsequently cause infarction in the posterior limb of the internal capsule and the basal ganglia parts supplied by the AChA. Ischemia in this territory can lead to severe neurological deficits such as hemiplegia (pyramidal tract), hemianesthesia (thalamus and thalamo-cortical fibers), and hemianopia (optic tract, lateral geniculate body, or geniculo-calcarine tract).

Usually, AChA origin occlusions do not lead to clinical sequelae because of the connections in the choroid fissure subtly showing less flow in the left genu/posterior limb of internal capsule (arrow), lentiform nucleus and temporal lobe area. Scale presented on right side of image. e: Cerebral blood volume map showing decreased volume in genu/posterior limb of internal capsule (arrow). f: 5-day follow-up non-contrast CT showing large infarct in the left internal capsule and temporal lobe

with the choroidal branches from the PCA [24]. The tolerance of AChA occlusion correlates with absence of AChA infarction or restriction of ischemia to the medial temporal artery area only [25]. Especially in case of anatomical variations of the AChA and PCA territories (illustrative case), an AChA origin occlusion could lead to enlargement of the ischemic area including involvement of the medial part of the temporal, occipital, and parietal lobes, resulting in a more profound neurological deficit. The illustrative case represents the Takahashi Type 2 variation: an anomalous temporal artery supplying the infero-medial part of the temporal lobe [26].

Several limitations of the current study should be noted. First, although to our knowledge this study describes the largest cohort of patients with carotid-I occlusions published so 
far, the low number of patients may result in accidental findings. Second, selection bias may have occurred in the nonEVT-treated group due to the retrospective, non-randomized nature of our data: the EVT-treated group was probably selected based on a more favorable profile in their baseline characteristics. We observed a lower age, lower pre-stroke mRS, and lower baseline NIHSS in EVT-treated patients. This could also explain the observation that patients with unsuccessful reperfusion (eTICI $0-1$ ) showed better functional outcome than patients in the non-EVT group. Third, occlusion location was scored on CTA in this study, whereas DSA can more accurately show occlusion pattern and patency of small branches. However, since the decision to treat endovascularly is made based on CTA in daily practice, we believe that this approach is more realistic and clinically applicable. Fourth, we have no data on recanalization status of non-EVT-treated patients, nor post-treatment parameters like blood pressure fluctuation, which was reported to be associated with penumbral tissue loss in non-recanalized patients [27]. Fifth, we excluded patients in whom isolated extracranial ICA occlusions were the cause of stroke. This was done to homogenize our study sample and focus on intracranial carotid-I occlusions, specifically. The patient group with acute ischemic stroke and isolated extracranial ICA occlusions poses a currently relevant clinical topic for further study. Finally, our findings are based on observational data. Ideally, randomized data without selection bias would be necessary to confirm the effect of EVT in patients with carotid-I occlusion and acute neurological deficit, though these data will be difficult to acquire due to the low prevalence of carotid-I occlusions. Our observations can serve as hypothesis generating for future studies on this topic.

\section{Conclusion}

In our population, we found overall improved outcomes after EVT in patients with a carotid-I occlusion and acute clinical symptoms, though the patients in our study sample with unsuccessful reperfusion or unsuccessfully retrieved distal emboli after EVT showed poor clinical outcomes. Our data suggest that EVT should be considered in carotid-I occlusion patients, though additional, ideally randomized, research would be necessary to confirm these findings.

Authors' contributions JWH and MK contributed equally to this paper.

Funding The current study received no funding. The MR CLEAN trial was supported by the Dutch Heart Foundation and by unrestricted grants from AngioCare Covidien/ev3, Medac/Lamepro, and Penumbra. The MR CLEAN Registry was funded and carried out by the Erasmus University Medical Centre, the Academic Medical Centre Amsterdam, and the Maastricht University Medical Centre. The Registry was additionally funded by the Applied Scientific Institute for Neuromodulation (Toegepast Wetenschappelijk Instituut voor Neuromodulatie).

\section{Compliance with ethical standards}

Conflict of interest BJE reports grants from Stryker Neurovascular and personal fees from Dekra and from Novartis outside the submitted work. CBLMM reports grants from TWIN during the conduct of the study and grants from CVON/Dutch Heart Foundation and from Stryker outside the submitted work (paid to institution). WHvZ reports personal fees from Cerenovus and from Stryker outside the submitted work. RvdB reports a consultancy agreement with Codman Depuy outside the submitted work. DWJD reports grants from the Dutch Heart Foundation, AngioCare, Medtronic/Covidien/EV3, MEDAC/LAMEPRO, Penumbra, Top Medical/Concentric, and Stryker during conduct of the study; consultation fees from Stryker, Bracco Imaging, and Servier, received by the Erasmus University Medical Centre, outside the submitted work. All other authors did not receive support from any organization for the submitted work, had no financial relationships with any organizations that might have an interest in the submitted work in the previous three years, and had no other relationships or activities that could appear to have influenced the submitted work.

Ethics approval The MR CLEAN Registry was evaluated by the central medical ethics committee of the Erasmus Medical Centre Rotterdam, the Netherlands, which granted permission to carry out the study as a Registry.

Consent to participate For this type of study, formal consent is not required. For included patients from the MR CLEAN trial, informed consent was obtained.

Consent for publication No identifying data was included in the current study.

Data transparency The data to reproduce or replicate the findings of this study cannot be made available since no patient approval was collected for sharing coded data. Summary data, syntaxes, and output files of summary statistics are available upon reasonable request.

Code availability Syntaxes and output files of summary statistics are available upon reasonable request.

Open Access This article is licensed under a Creative Commons Attribution 4.0 International License, which permits use, sharing, adaptation, distribution and reproduction in any medium or format, as long as you give appropriate credit to the original author(s) and the source, provide a link to the Creative Commons licence, and indicate if changes were made. The images or other third party material in this article are included in the article's Creative Commons licence, unless indicated otherwise in a credit line to the material. If material is not included in the article's Creative Commons licence and your intended use is not permitted by statutory regulation or exceeds the permitted use, you will need to obtain permission directly from the copyright holder. To view a copy of this licence, visit http://creativecommons.org/licenses/by/4.0/.

\section{References}

1. Goyal M, Menon BK, van Zwam WH, Dippel DWJ, Mitchell PJ, Demchuk AM, Dávalos A, Majoie CBLM, van der Lugt A, de Miquel MA, Donnan GA, Roos YBWEM, Bonafe A, Jahan R, Diener HC, van den Berg LA, Levy EI, Berkhemer OA, Pereira VM, Rempel J, Millán M, Davis SM, Roy D, Thornton J, Román LS, Ribó M, Beumer D, Stouch B, Brown S, Campbell BCV, van 
Oostenbrugge RJ, Saver JL, Hill MD, Jovin TG (2016) Endovascular thrombectomy after large-vessel ischaemic stroke: a meta-analysis of individual patient data from five randomised trials. Lancet 387:17231731. https://doi.org/10.1016/S0140-6736(16)00163-X

2. Nogueira RG, Jadhav AP, Haussen DC, Bonafe A, Budzik RF, Bhuva P, Yavagal DR, Ribo M, Cognard C, Hanel RA, Sila CA, Hassan AE, Millan M, Levy EI, Mitchell P, Chen M, English JD, Shah QA, Silver FL, Pereira VM, Mehta BP, Baxter BW, Abraham MG, Cardona P, Veznedaroglu E, Hellinger FR, Feng L, Kirmani JF, Lopes DK, Jankowitz BT, Frankel MR, Costalat V, Vora NA, Yoo AJ, Malik AM, Furlan AJ, Rubiera M, Aghaebrahim A, Olivot JM, Tekle WG, Shields R, Graves T, Lewis RJ, Smith WS, Liebeskind DS, Saver JL, Jovin TG, DAWN Trial Investigators (2017) Thrombectomy 6 to 24 hours after stroke with a mismatch between deficit and infarct. N Engl J Med 378:11-21. https://doi. org/10.1056/nejmoa1706442

3. Albers GW, Marks MP, Kemp S, Christensen S, Tsai JP, OrtegaGutierrez S, McTaggart R, Torbey MT, Kim-Tenser M, LeslieMazwi T, Sarraj A, Kasner SE, Ansari SA, Yeatts SD, Hamilton S, Mlynash M, Heit JJ, Zaharchuk G, Kim S, Carrozzella J, Palesch YY, Demchuk AM, Bammer R, Lavori PW, Broderick JP, Lansberg MG, DEFUSE 3 Investigators (2018) Thrombectomy for stroke at 6 to 16 hours with selection by perfusion imaging. N Engl J Med 378:708718. https://doi.org/10.1056/NEJMoa1713973

4. Van den Berg LA, Dijkgraaf MGW, Berkhemer OA, Fransen PSS, Beumer D, Lingsma HF, Majoie CBLM, Dippel DWJ, van der Lugt A, van Oostenbrugge RJ, van Zwam WH, Roos YBWEM, for the MR CLEAN Investigators (2017)Two-year outcome after endovascular treatment for acute ischemic stroke. N Engl J Med 376:1341-1349. https://doi.org/10.1056/NEJMoa1612136

5. Liebeskind DS, Flint AC, Budzik RF, Xiang B, Smith WS, Duckwiler GR, Nogueira NG, for the MERCI and Multi-MERCI Investigators (2015) Carotid I's, L's and T's: collaterals shape the outcome of intracranial carotid occlusion in acute ischemic stroke. J Neurointerv Surg 7: 402-407. https://doi.org/10.1136/neurintsurg-2014-011231

6. Ois A, Cuadrado-Godia E, Solano A, Perich-Alsina X, Roquer J (2009) Acute ischemic stroke in anterior choroidal artery territory. J Neurol Sci 281:80-84. https://doi.org/10.1016/j.jns.2009.02.323

7. Alqahtani SA, Luby M, Nadareishvili Z et al (2017) Perfusion deficits and association with clinical outcome in patients with anterior choroidal artery stroke. J Stroke Cerebrovasc Dis 26:17551759. https://doi.org/10.1007/s10741-014-9462-7

8. Kurre W, Vorlaender K, Aguilar-Perez M et al (2013) Frequency and relevance of anterior cerebral artery embolism caused by mechanical thrombectomy of middle cerebral artery occlusion. Am J Neuroradiol 34:1606-1611. https://doi.org/10.3174/ajnr.A3462

9. Powers WJ, Rabinstein AA, Ackerson T et al (2019) Guidelines for the early management of patients with acute ischemic stroke: 2019 update to the 2018 guidelines for the early management of acute ischemic stroke: a guideline for healthcare professionals from the American Heart Association/American Stroke Association. Stroke 50:e344-e418. https://doi.org/10.1161/STR.0000000000000211

10. Berkhemer OA, Fransen PS, Beumer D et al (2015) A randomized trial of intraarterial treatment for acute ischemic stroke. N Engl J Med 372:11-20. https://doi.org/10.1056/NEJMoa1411587

11. Goyal M, Demchuk AM, Menon BK, Eesa M, Rempel JL, Thornton J, Roy D, Jovin TG, Willinsky RA, Sapkota BL, Dowlatshahi D, Frei DF, Kamal NR, Montanera WJ, Poppe AY, Ryckborst KJ, Silver FL, Shuaib A, Tampieri D, Williams D, Bang OY, Baxter BW, Burns PA, Choe H, Heo JH, Holmstedt CA, Jankowitz B, Kelly M, Linares G, Mandzia JL, Shankar J, Sohn SI, Swartz RH, Barber PA, Coutts SB, Smith EE, Morrish WF, Weill A, Subramaniam S, Mitha AP, Wong JH, Lowerison MW, Sajobi TT, Hill MD, ESCAPE Trial Investigators (2015) Randomized assessment of rapid endovascular treatment of ischemic stroke. N Engl J Med 372:1019-1030. https://doi.org/10. 1056/NEJMoa1414905
12. Saver JL, Goyal M, Bonafe A, Diener HC, Levy EI, Pereira VM, Albers GW, Cognard C, Cohen DJ, Hacke W, Jansen O, Jovin TG, Mattle HP, Nogueira RG, Siddiqui AH, Yavagal DR, Baxter BW, Devlin TG, Lopes DK, Reddy VK, du Mesnil de Rochemont R, Singer OC, Jahan R, SWIFT PRIME Investigators (2015)Stentretriever thrombectomy after intravenous t-PA vs. t-PA alone in stroke. N Engl J Med 372:2285-2295. https://doi.org/10.1056/ NEJMoa1415061

13. Jovin TG, Chamorro A, Cobo E, de Miquel MA, Molina CA, Rovira A, San Román L, Serena J, Abilleira S, Ribó M, Millán M, Urra X, Cardona P, López-Cancio E, Tomasello A, Castaño C, Blasco J, Aja L, Dorado L, Quesada H, Rubiera M, Hernandez-Pérez M, Goyal M, Demchuk AM, von Kummer R, Gallofré M, Dávalos A (2015) Thrombectomy within 8 hours after symptom onset in ischemic stroke. N Engl J Med 372:2296-2306. https://doi.org/10.1056/NEJMoa1503780

14. Jansen IGH, Mulder MJHL, Goldhoorn RJB (2018) Endovascular treatment for acute ischaemic stroke in routine clinical practice: prospective, observational cohort study (MR CLEAN Registry). BMJ 360:k949. https://doi.org/10.1136/bmj.k949

15. Kim Y-W, Kang D-H, Kim Y-S, Hwang Y-H(2019) Efficacy and safety of endovascular treatment in patients with internal carotid artery occlusion and collateral middle cerebral artery flow. J Korean Neurosurg Soc 62:201-208. https://doi.org/10.3340/jkns. 2018.0144

16. Koge J, Matsumoto S, Nakahara I, Ishii A, Hatano T, Tanaka Y, Kondo D, Kira JI, Nagata I (2020) Impact of thrombus migration on clinical outcomes in patients with internal carotid artery occlusions and patent middle cerebral artery. J Neurol Sci 412:116737. https:// doi.org/10.1016/j.jns.2020.116737

17. Van Rooij WJ, Sluzewski M, Slob MJ, Rinkel GJ (2005) Predictive value of angiographic testing for tolerance to therapeutic occlusion of the carotid artery. Am J Neuroradiol 26:175-178

18. Cechetti F, Pagnussat AS, Worm PV, Elsner VR, Ben J, da Costa MS, Mestriner R, Weis SN, Netto CA (2012) Chronic brain hypoperfusion causes early glial activation and neuronal death, and subsequent long-term memory impairment. Brain Res Bull 87:109116. https://doi.org/10.1016/j.brainresbull.2011.10.006

19. American Society of Interventional and Therapeutic Neuroradiology (2001) Carotid artery balloon test occlusion. Am J Neuroradiol 22(8 Suppl):S8-S9

20. Moore O, Baker HW (1955) Carotid-artery ligation in surgery of the head and neck. Cancer 8:712-726. https://doi.org/10.1002/ 1097-0142(1955)8:4<712::AID-CNCR2820080414>3.0.CO;2-L

21. Moore OS, Karlan M, Sigler L (1969) Factors influencing the safety of carotid ligation. Am J Surg 118:666-668. https://doi.org/10. 1016/0002-9610(69)90209-8

22. Norlen G (1951) The pathology, diagnosis and treatment of intracranial saccular aneurysms. Proc R Soc Med 45:291-302

23. Chun On Tsang A, Orru E, Klostranec JM et al (2019) Thrombectomy outcomes of intracranial atherosclerosis-related occlusions. Stroke 50:1460-1466. https://doi.org/10.1161/ STROKEAHA.119.024889

24. Abbie AA (1933) The clinical significance of the anterior choroidal artery. Brain 56:233-246. https://doi.org/10.1097/00000441191701000-00004

25. Lee M, Saver JL, Hao Q, Starkman S, Salamon N, Ali LK, Kim D, Ovbiagele B, Song S, Raychev R, Abcede H, Fiaz R, Liebeskind DS, for the UCLA Stroke Investigators (2012) Anterior choroidal artery ischaemic patterns predict outcome of carotid occlusion. J Neurol Neurosurg Psychiatry 83:586-590. https://doi.org/10. 1136/jnnp-2011-301493

26. Takahashi S, Suga T, Kawata Y, Sakamoto K (1990) Anterior choroidal artery: angiographic analysis of variations and anomalies. Am J Neuroradiol 11:719-729 
27. Jeong HG, Kim BJ, Kim H, Jung C, Han MK, Liebeskind DS, Bae HJ (2019) Blood pressure drop and penumbral tissue loss in nonrecanalized emergent large vessel occlusion. Stroke 50:26772684. https://doi.org/10.1161/STROKEAHA.119.025426
Publisher's note Springer Nature remains neutral with regard to jurisdictional claims in published maps and institutional affiliations. 